\title{
Spectral transmittance of the spectacle scale of snakes and geckos
}

\author{
Kevin van Doorn ${ }^{1,2}$, Jacob G. Sivak ${ }^{1}$ \\ ${ }^{1}$ School of Optometry and Vision Science, Faculty of Science, University of Waterloo, 200 University Avenue West, \\ Waterloo, Ontario, Canada N2L $3 G 1$ \\ ${ }^{2}$ E-mail: kevin.vandoorn@uwaterloo.ca
}

Key words: Gekkonidae, keratin, Serpentes, Squamata

\begin{abstract}
The spectral transmittance of the optical media of the eye plays a substantial role in tuning the spectrum of light available for capture by the retina. Certain squamate reptiles, including snakes and most geckos, shield their eyes beneath a layer of transparent, cornified skin called the 'spectacle'. This spectacle offers an added opportunity compared with eyelidded animals for tayloring the spectrum. In particular, the hard scale that covers the surface of the spectacle provides a unique material, keratin, rarely found in vertebrate eyes, a material which may have unique spectral properties. To verify this, shed snake and gecko skins were collected and the spectral transmittance of spectacle scales was spectrophotometrically analyzed. The spectacle scale was found generally to behave as a highpass filter with a cut-off in the ultraviolet spectrum where taxonomic variation is mostly observed. The spectacle scales of colubrid and elapid snakes were found to exhibit higher cut-off wavelengths than those of pythonids, vipers, and most boids. Gecko spectacle scales in turn exhibited exceptional spectral transmittance through the visual spectrum down into the UV-B. It is suggested that this is due to the absence of beta-keratins in their spectacle scale.
\end{abstract}

\section{Contents}

Introduction …………………………………………………..... 1

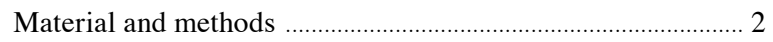

Sample collection ……………………………………………........ 2

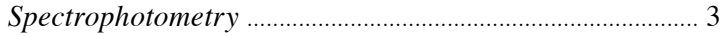

Thickness measurements …………………………………….... 3

Analytical methods ……………………………………......... 3

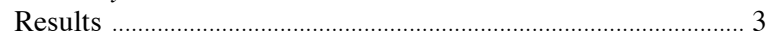

Snake spectacle scale transmittance ………………………... 3

Gecko spectacle scale transmittance ………………………... 3

Spectacle scale thickness ........................................................ 5

Relationship between spectacle scale thickness and $\lambda_{50 \%} \ldots 5$

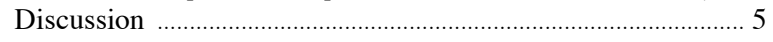

Spectacle scale transmittance: taxonomic variation ......... 5

Considering the spectacle scale's role as an optical filter .. 7

Considering the spectacle scale's role as mechanical

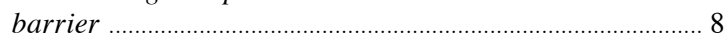

Gecko versus snake spectacle scales and a discussion of

keratin composition

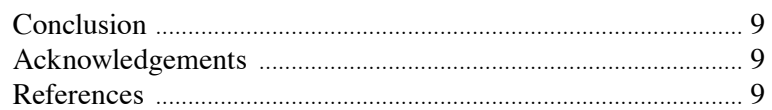

\section{Introduction}

The optical media of the eye play a crucial role in tuning the spectrum of light incident upon the retina. For example, tissues may filter out short wavelengths of the blue and ultraviolet (UV) ranges to increase image contrast or block harmful radiation, such as occurs with the yellow crystalline lenses of some squirrels (Walls, 1931; Chou and Cullen, 1984), squamate reptiles (Walls, 1942; Röll et al., 1996; Röll, 2000) and fishes (Walls and Judd, 1933; Kennedy and Milkman, 1956; Muntz, 1973).

The spectral transmittance and absorption of various ocular media (i.e. the cornea, lens, neural retina, and aqueous and vitreous humours) have been studied in all vertebrate taxa (reviewed in Douglas and Marshall, 1999), although data on reptiles remains somewhat limited (Ellingson et al., 1995; Bowmaker et al., 2005), and the reptilian spectacle, despite its unique position in the optics of squamate eyes, has received surprisingly little attention (Safer et al., 2007; Hart et al., 2012).

The spectacle is a layer of transparent skin that covers the eyes of many squamates, including all snakes and most geckos (Fig. 1; Walls, 1942). Despite being the primary window through which these animals see, very few studies have investigated the spectral properties of the spectacle. Hart et al. (2012) and Safer et al. (2007) respectively reported on the transmittance of hydrophiid sea snake spectacles and rattlesnake spectacle scales, the former measuring in the visible and UV range while the latter focused on the infrared spectrum, which is not of visual relevance. Given the unusual nature of the reptilian spectacle as an extra layer in the 

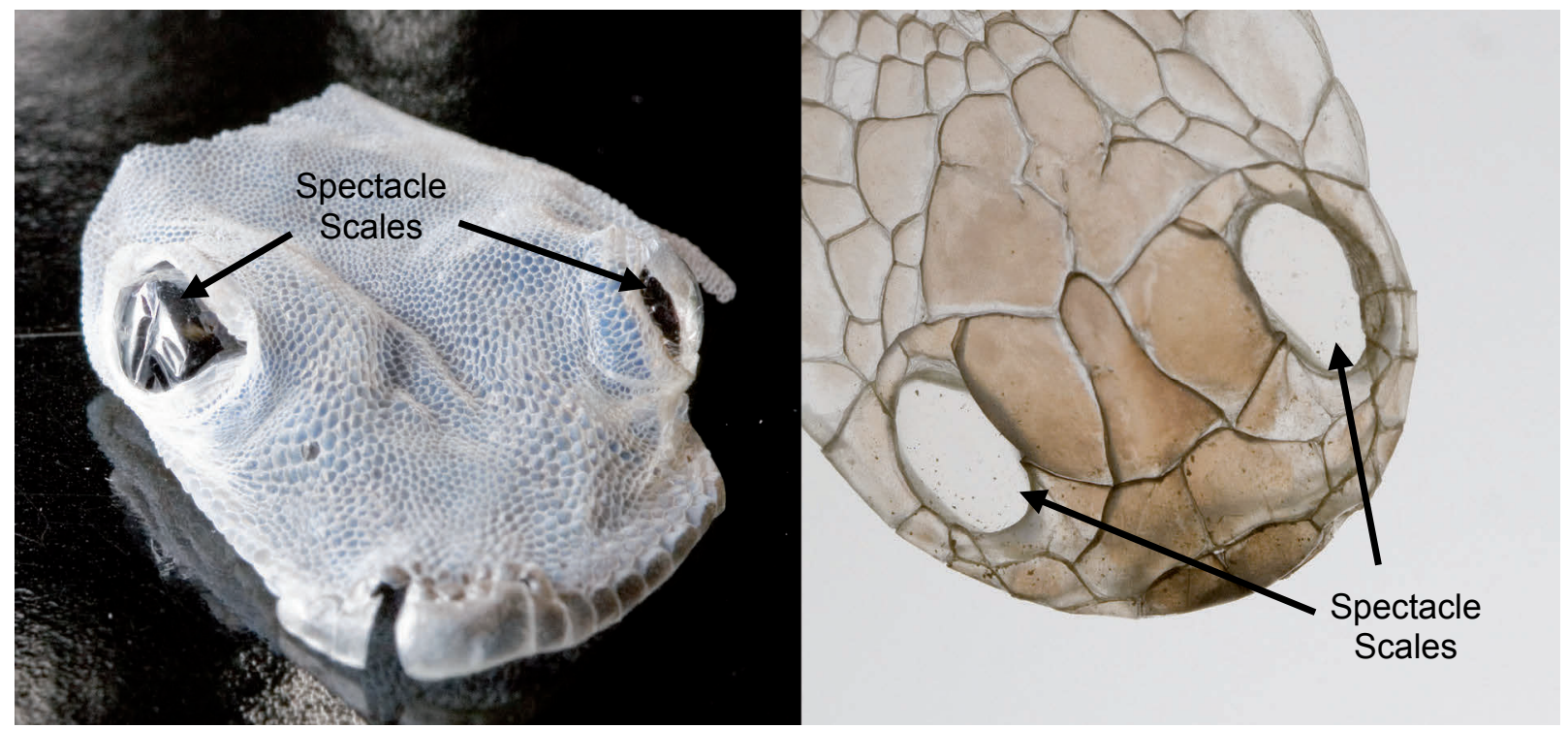

Fig. 1. Shed gecko (left) and snake (right) skins showing the dorsal head region and indicating the spectacle scales. Compared with other scales which are translucent at best and may be pigmented, the spectacle scales are optically transparent.

optical apparatus of the eye which may further absorb or reflect wavelengths that are unnecessary for or deleterious to an animal's vision (e.g. due to chromatic aberration or scatter, Sivak, 1982; Sivak and Mandelman, 1982), an investigation of its optical properties over a broad range of species may be beneficial to better understand its contribution to vision in squamates.

Reptilian spectacles consist of soft tissues (dermal stroma, epidermal epithelia, and conjunctiva) and hard keratin (the stratum corneum, referred to as the 'spectacle scale'). The dermal stroma of the spectacle is similar to the cornea with its lamellar arrangement of highly organized collagen fibers (Da Silva et al., 2014) and is thus likely to exhibit similar spectral properties. The spectacle scale however presents a unique material in the optics of the eye, as keratinizing epithelia are typically absent from vertebrate eyes (the few known exceptions being the ant- or termite-eating echidna (Tachyglossus Illiger, 1811), armadillo (Dasypus Linnaeus, 1758) and aardvark (Orycteropus $\mathrm{G}$. Cuvier, 1798), all of which are reported to possess keratinized corneas (Walls, 1942; Duke-Elder, 1958)).

As a result of its unique composition, the spectacle scale itself may exhibit unique spectral properties and provide a unique opportunity in the evolution of ocular filtering. Previous research by van Doorn et al. (2014) has shown that the biochemical composition of spectacle scales varies taxonomically, differing between species and particularly between families, as well as be- tween snakes and geckos, the latter of which lack one whole class of keratin proteins (the beta-keratins) thought to otherwise be present in all squamate scales (Maderson, 1985; Landmann, 1986). Thus if keratins vary in their transmissive properties, one could theorize that the spectral transmittance of spectacle scales may vary between snake families and between snakes and geckos. The research presented here, a study of the spectral transmittance of shed snake and gecko spectacle scales, provides evidence that this is the case.

\section{Material and methods}

The experiments described here consisted of spectrophotometric measurements of snake and gecko spectacle scales collected from shed skins. Because the spectral transmittance of a material typically correlates with its thickness, spectacle scale thicknesses were also measured.

\section{Sample collection}

Spectacle scales from 43 species of snake (6 boids, 7 pythonids, 10 viperids, 3 elapids, and 17 colubrids) and 2 species of gekkonid gecko were investigated. These were collected from shed skins donated by private pet owners and zoos. The species investigated, including all specimens of particular species, along 
with the species' authorities are summarized in Table 1. Because moulting snakes frequently soak themselves to soften the skin prior to shedding, the sheds were air dried upon collection and stored for up to 2 months in paper envelopes to prevent spoilage. When kept under such conditions, spectacle scales have been found to retain their spectral properties over very long periods, up to and including several years (van Doorn, unpubl. data).

\section{Spectrophotometry}

Spectacle scales were cut from the sheds and mounted with adhesive tape to a sample holder equipped with either an $8 \mathrm{~mm}$ aperture for larger scales or a $1 \mathrm{~mm}$ aperture for smaller scales. The sample holder was placed within a Varian Cary 500 UV-VIS-IR dualbeam spectrophotometer such that the scanning beam was passed through the scale from front to back (i.e. the beam was incident upon the outer surface). Measurements were made from 200 to $750 \mathrm{~nm}$ in $2 \mathrm{~nm}$ increments. Published reports of keratin's transmittance in both dry and wet states (Bendit and Ross, 1961; Bruls et al., 1984) have shown that hydration has a minor effect on transmittance and that it doesn't change the overall profile of transmittance curves. This is likely due to the spectral properties of water itself, notably that it exhibits modest absorption of long wavelengths (i.e. in the red range) and very short wavelengths (i.e. in the deep UV range), as well as its capability as a thin film to reduce optical scatter by 'smoothing out' surface irregularities of the material. As a result, all scans of shed spectacle scales in these experiments were performed dry, particularly because the long scan times resulted in hydrated scales drying out mid-scan anyway, which could lead to slight deformation of the scale and small spurious vertical shifts in spectral transmittance. The measurements from both the right and left eyes of each specimen were averaged unless the shed had only one usable spectacle scale, in which case the reported measurements consist of solely the one.

\section{Thickness measurements}

A gauge designed for measuring the thickness of hard contact lenses was used to measure the thickness of the spectacle scales. Some scales were unavailable for thickness measurements, including those of the 3 elapids, due to having been used in an unrelated experiment.

\section{Analytical methods}

The $50 \%$ cut-off wavelength $\left(\lambda_{50 \%}\right)$, the boundary beneath which $>50 \%$ of the incident light is attenuated (either by absorption, reflection or scatter), was determined for each sample from the raw data and rounded to the nearest integer. To even the representation of species in the analyses, specimens were weighted $1 / \mathrm{n}$, where $\mathrm{n}$ is the number of specimens of a particular species that were available to a given test (N.B.: n may be lower for thickness analyses than for transmittance analyses due to availability of the scales as noted above). To determine if $\lambda_{50 \%}$ and spectacle scale thickness vary between families, Kruskal-Wallis analysis of variance on ranks was performed. Dunn's method of multiple comparisons was used to clarify which families differed from which. A correlation on ranks (Spearman's Rho) of $\lambda_{50 \%}$ versus thickness was calculated to determine how much the latter contributes to the former. All analyses were done with Statistica 11.

\section{Results}

\section{Snake spectacle scale transmittance}

The spectral transmittance curves of all snake spectacle scale samples are plotted in Fig. 2. In most species, the spectacle transmittance is relatively high from the far red to the near UV-A, although in many cases there is a slight reduction from long to short wavelengths. Most variation occurs within the UV range, with the cut-off wavelengths varying noticeably between species and families. The $\lambda_{50 \%}$ of individual sheds are reported in Table 1 . The $\lambda_{50 \%}$ means, minima and maxima for each family are listed in Table 2 with a box plot shown in Fig. 3. Because Fig. 2 is too cluttered to allow proper evaluation of individual curves, the transmittance curves of a few representative species and outliers from each family are plotted in Figures 4A-E to aid with visual inspection.

Boas generally have low $\lambda_{50 \%}$ 's as represented in Fig. 4A by Boa constrictor and the Garden Tree Boa. Two exceptions to this are the Green Anaconda and the Rubber Boa (the only erycine boa sampled), both of which exhibit higher cut-offs as well as a modest degree of attenuation of most wavelengths. The characteristic peak at $254 \mathrm{~nm}$ is also absent in the green anaconda.

Colubrids, represented here mostly by North American colubrine species, tend to exhibit higher $\lambda_{50 \%}$ 's similar to the Eastern Coachwhip and the Taiwan 


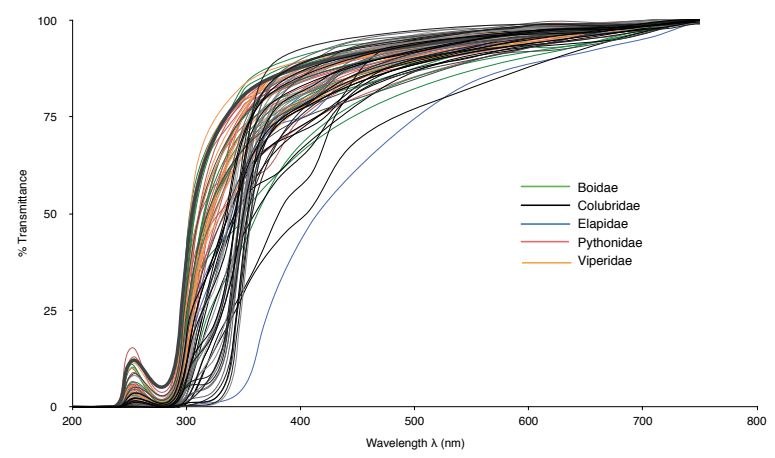

Fig. 2. Spectral transmittance curves of all sampled snakes, colour-coded by family. Taxonomic variation is evident, particularly at the cut-off in the ultraviolet range.

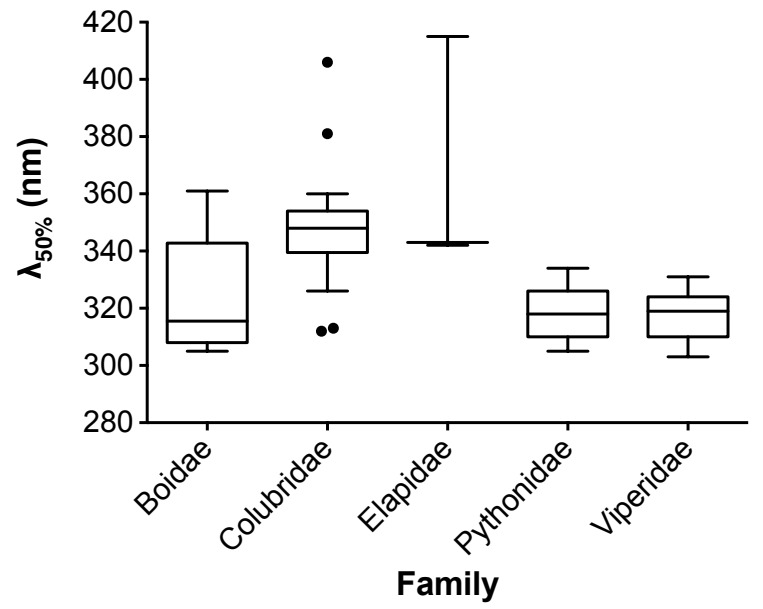

Fig. 3. $\lambda_{50 \%}$ grouped by family showing median (horizontal line), $25 \%$ and $75 \%$ percentiles and whiskers drawn according to Tukey's method. Statistical outliers in Colubridae are Heterodon platirhinos (higher $\lambda 50 \%$ ) and Lampropeltis alterna (lower $\lambda 50 \%)$.
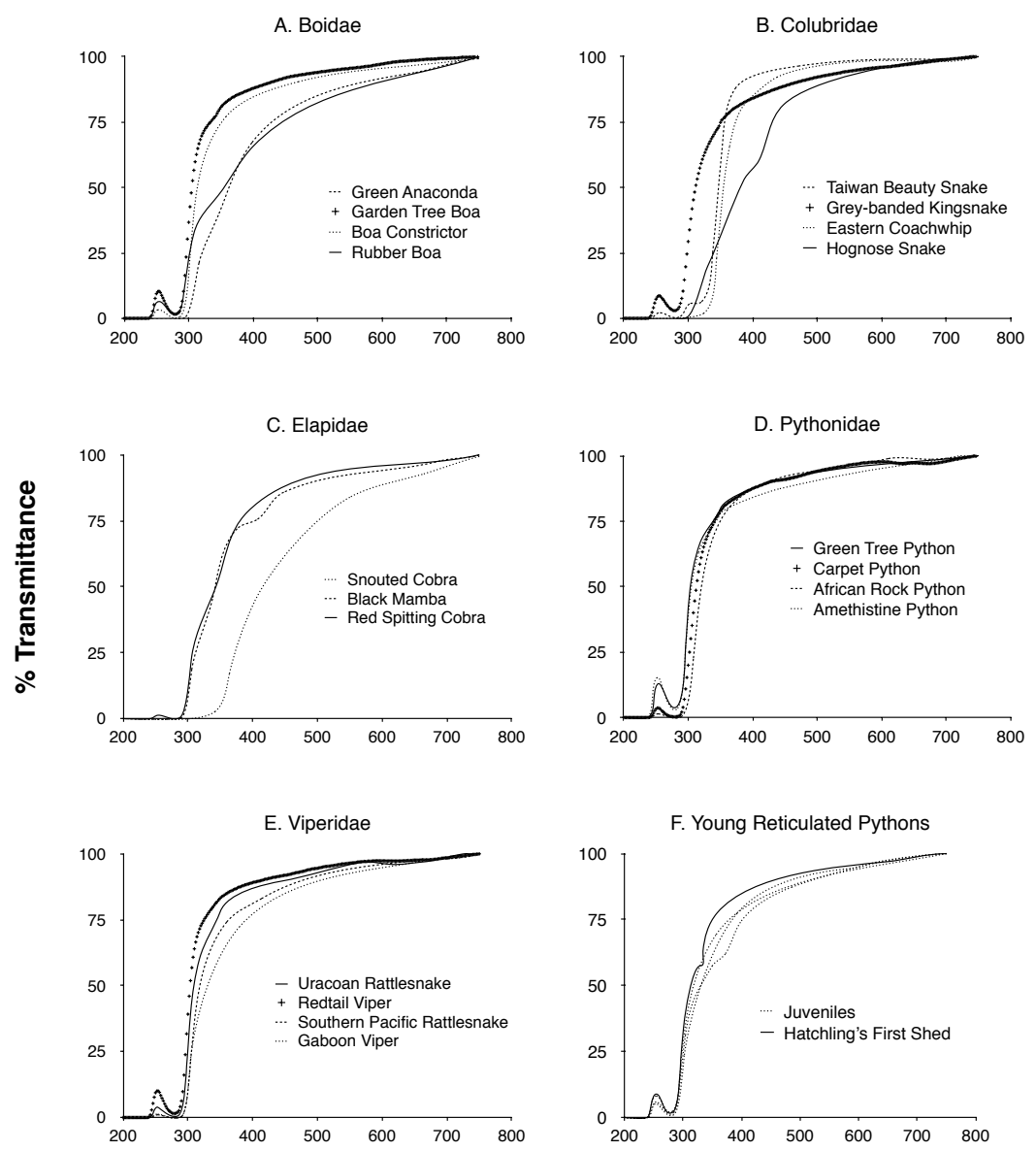

Wavelength $\lambda(\mathrm{nm})$

Fig. 4A-F. Transmittance spectra of representative species and outliers within each sampled family. 
Beauty Snake shown in Fig. 4B. The genus Lampropeltis with a markedly lower $\lambda_{50 \%}$ is an exception to this and unlike most of the rest it also exhibits a small peak at $254 \mathrm{~nm}$. The only xenodontine colubrid in the sample, the Hognose Snake, has a higher $\lambda_{50 \%}$ than colubrine species. Its spectacle scale has a slightly brownish tint.

Elapids exhibit comparable mean $\lambda_{50 \%}$ 's with colubrids (compare the black mamba and red spitting cobra in Fig. 4C) and like them the $254 \mathrm{~nm}$ peak is largely absent. Their profiles nevertheless differ in that they still transmit some short wavelength UV-A (their $\lambda_{10 \%}$ 's are lower than colubrids'). A notable exception is the Snouted Cobra, which has a conspicuously yellow spectacle scale. Its $\lambda_{50 \%}$ is quite high as a result and in addition to blocking much UV it exhibits significant attenuation of the blue region.

All the sampled pythons demonstrate high transmittance through the UV-A and had quite low $\lambda_{50 \%}$ (Fig. 4D). Several also showed notable peaks at 254 nm.

Vipers (Fig. 4E) exhibit similar profiles to pythons and most boids. Though all but one species represented here are crotaline vipers, the one exception, the Gaboon Viper (Subfamily Viperinae) has a similar profile though technically its $\lambda_{50 \%}$ is higher.

The transmittance spectra of hatchling and juvenile Reticulated Pythons (Python reticulatus) are plotted in Fig. 4F. Broadly similar in profile to more mature animals, the hatchling shed does exhibit slightly higher transmittance in the UV-A and a peculiar 'hump' at $320 \mathrm{~nm}$ not otherwise seen in other sheds.

Kruskal-Wallis analysis indicates that spectacle scale $\lambda_{50 \%}$ significantly varies between families ( $\mathrm{p}<$ 0.0001) and Dunn's multiple comparisons show that colubrids alone account for this by differing significantly from boids, pythonids and viperids $(\mathrm{p}<0.05)$ but not elapids ( $p>0.9999)$. No other comparison is statistically significant.

\section{Gecko spectacle scale transmittance}

The spectral transmittance of gecko spectacle scales (Fig. 5), in sharp contrast with those of snakes, exhibits exceptionally high transmittance from the red far down into the UV-B without significant tapering of the curves until they drop to $\sim 37-53 \%$ at $\sim 290 \mathrm{~nm}$ before peaking again to $\sim 60-70 \%$ at $254 \mathrm{~nm}$ and finally cutting off completely at $\sim 240 \mathrm{~nm}$.

\section{Spectacle scale thickness}

The thicknesses of individual spectacle scales are reported in Table 1 and median thicknesses for each family are plotted in Fig. 6 . As with $\lambda_{50 \%}$, thickness varies between families $(\mathrm{p}<0.0001)$ and again colubrids contribute to this by differing from boids, pythonids and viperids $(\mathrm{p}<0.05)$.

Relationship between spectacle scale thickness and $\lambda_{50 \%}$

Fig. 7 shows spectacle scale thickness plotted against $\lambda_{50 \%}$ for all measured samples. The correlation is significant $(\mathrm{p}<0.0001)$ and fairly strong (Spearman's rho $=0.784)$.

\section{Discussion}

The purpose of this study was to determine if variation exists in the transmittance spectra of spectacle scales and, if so, whether taxonomic relationships, ecological factors and/or known biochemical composition could account for observed differences. Indeed, significant differences in both transmittance and thickness were found between snakes and geckos, between snake families and subfamilies, and unique spectra were observed in a few species, attesting to the diversity of which the spectacle is capable and its significance in tuning the spectrum of incident light.

\section{Spectacle scale transmittance: taxonomic variation}

Most of the observed transmittance spectra are characterized by high transmittance in the far red to near UV-A ranges but differ in the middle UV-A as evidenced by the variation in cut-off wavelengths. A marked difference was observed between colubrids and pythonids, viperids and most boids (other than the Green Anaconda and Rubber Boa). The high $\lambda_{50 \%}$ of elapids seems to parallel that of colubrids, although visual inspection of their transmittance curves shows they lack the sharp cut-off of most colubrids and instead exhibit gradual reduction of transmittance (compare for example the $\lambda_{10 \%}$ of the Red Spitting Cobra with that of a representative Coachwhip Snake: 298 $\mathrm{nm}$ vs $327 \mathrm{~nm}$ ).

It should be borne in mind that most of the samples within any given family were from a specific subfamily, and indeed from a restricted number of genera. 
Table 2. Mean spectacle scale $\lambda_{50 \%}$ for each snake family and subfamily as well as minima and maxima. Erycinae and Viperinae were represented by only one species, and Xenodontinae by 3 specimens of one species.

\begin{tabular}{lllll}
\hline Family & Subfamily & Mean $\lambda 50 \%(\mathrm{~nm})$ & Min $\lambda 50 \%$ & Max $\lambda 50 \%$ \\
\hline Boidae & & 323 & 305 & 361 \\
& Boinae & 319 & 305 & 361 \\
& Erycinae (Charina bottae) & 351 & $\mathrm{n} / \mathrm{a}$ & $\mathrm{n} / \mathrm{a}$ \\
Colubridae & & 312 & 406 \\
& Colubrinae & 345 & 312 & 358 \\
& Xenodontinae & 382 & 360 & 406 \\
& (Heterodon platirhinos) & & & \\
Elapidae & & 367 & 342 & 415 \\
Pythonidae & & 315 & 305 & 334 \\
Viperidae & & 317 & 303 & 331 \\
& Crotalinae & 316 & 303 & 325 \\
& Viperinae (Bitis gabonica) & 331 & $\mathrm{n} / \mathrm{a}$ & $\mathrm{n} / \mathrm{a}$ \\
\hline
\end{tabular}

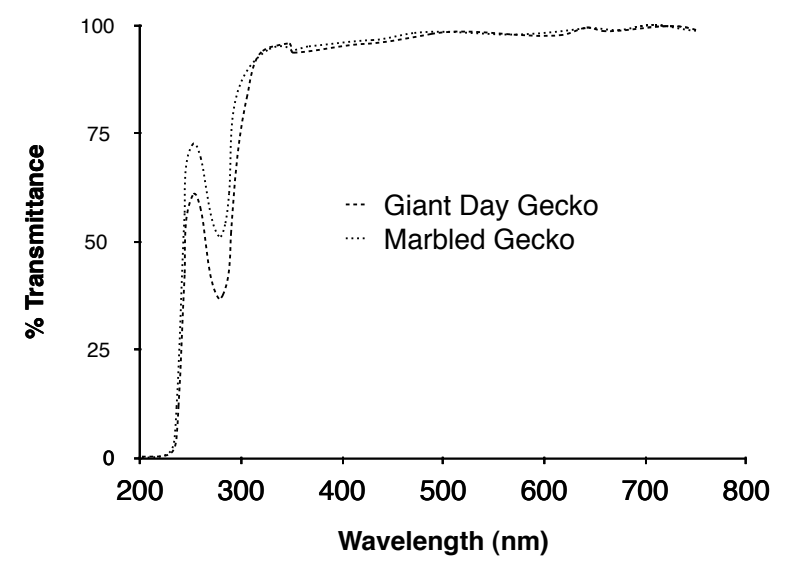

Fig. 5. Spectacle scale transmittance spectra in gekkonid geckos. Gecko spectacles exhibit exceptionally high transmittance through the visible and UV spectra, close to or at $100 \%$ until dropping somewhat in the UV-B, before peaking again at $254 \mathrm{~nm}$ in the UV-C.

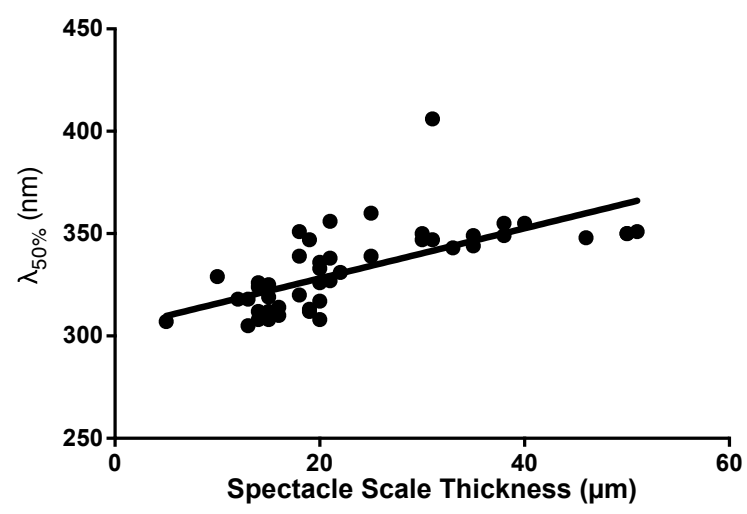

Fig. 7. Correlation and regression plot of $\lambda 50 \%$ versus spectacle scale thickness. Data from all families are pooled and show a positive and significant correlation (Spearman's rho $=0.784, \mathrm{p}<$ $0.05)$. A linear regression line is drawn to assist in visualizing the trend.

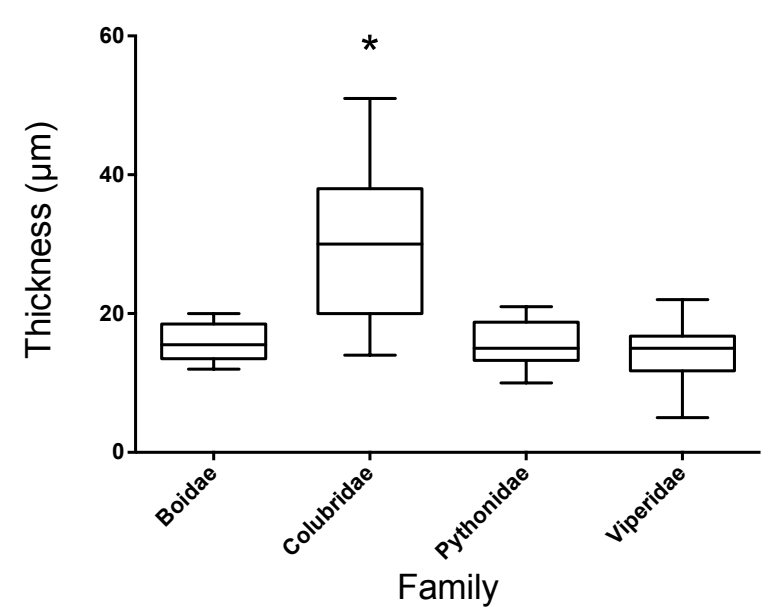

Fig. 6. Plot of spectacle scale thicknesses grouped by family. The boxes show the median and 25th and 75th percentiles and the whiskers are drawn according to Tukey's method. Means are respectively $16 \mu \mathrm{m}, 30 \mu \mathrm{m}, 16 \mu \mathrm{m}$ and $14 \mu \mathrm{m}$ for Boidae, Colubridae, Pythonidae and Viperidae. Colubridae is seen to differ significantly from the other families in having a greater mean spectacle scale thickness $(\mathrm{K}-\mathrm{W} \mathrm{p}<0.0001)$. In no other family does the highest value match or exceed the Colubridae mean (note that no elapids could be measured here).

Some subfamilies represented here by a single species tend to demonstrate rather different transmittance spectra compared with the well represented subfamily. For example, among the colubrids, the xenodontine hognose snake showed the highest $\lambda_{50 \%}$ (mean: $382 \mathrm{~nm}$, max: $406 \mathrm{~nm}$ ), attenuating much of the UV-A spectrum. Likewise among boids, the erycine Rubber Boa is second only to the Green Anaconda in its high $\lambda_{50 \%}$ ( $351 \mathrm{~nm}$ versus $361 \mathrm{~nm}$, compared with a mean of 324 $\mathrm{nm}$ for the family as a whole), and the Gaboon Viper 
has a higher $\lambda_{50 \%}$ than all crotaline vipers (331 nm versus a mean of $317 \mathrm{~nm}$ ). These findings warrant further investigation to determine if they are representative of their respective subfamilies.

Spectacle scales' $\lambda_{50 \%}$ correlates with their thickness although it's unclear if thickness is the cause and $\lambda_{50 \%}$ the effect. The association may be indirect by virtue of both being characteristic of certain families, begging the question of why colubrid spectacle scales generally are thicker and have higher $\lambda_{50 \%}$ than other families, elapids and specific boids excluded. Also, according to the Spearman's Rho of $0.784, \lambda_{50 \%}$ and thickness are not perfectly related, so other factors may be at play here. To speculate on this, a consideration of the functional adaption of spectacle scale $\lambda_{50 \%}$ and thickness is called for.

\section{Considering the spectacle scale's role as an optical filter}

Coloured 'filters' are present in the eyes of many species: the pigmented or iridescent corneas of numerous reef fish, the yellow lenses of some fish, squirrels and diurnal reptiles, the macula lutea of primates, and the photoreceptor oil droplets of birds and reptiles (Walls, 1942; Lythgoe, 1979; Douglas and Marshall, 1999; Hart, 2001). These are often associated with diurnal activity and are suggested to block harmful short wavelength radiation, to improve image contrast by removing shorter wavelengths that are more likely to scatter, or in the case of oil droplets to fine tune photoreceptor absorbance spectra to improve colour discrimination (reviewed in Douglas and Marshall, 1999). The spectacle scale's contribution to overall transmittance of the eye is limited in most species to blocking the mid to far UV-A and UV-B, excepting the Snouted Cobra, Hognose Snake, and adult Spine-Bellied Sea Snake (Lapemis curtus (Shaw, 1802), Hart et al., 2012), all of which block much UV-A and some of the blue region of the spectrum.

While the UV-A region spans a broad range from $315-400 \mathrm{~nm}$, vision in this region will be restricted to the specific spectral absorbances of an animal's retinal opsins. Several species of snake and gecko are known to possess UV-A sensitive cones (Loew, 1994; Ellingson et al., 1995; Loew et al., 1996; Sillman et al., 1997., 1999., 2001; Davies et al., 2009; Macedonia et al., 2009; Yang, 2010; Hart et al., 2012), suggesting that the visual perception of UV-A wavelengths is a common trait throughout these taxa. The retinal absorbance spectra of four snakes included in this study have been previously characterized (Thamnophis sirtalis (Sillman et al., 1997), Python regius (Sillman et al., 1999), Boa constrictor (Sillman et al., 2001), and Masticophis flagellum (Macedonia et al., 2009)) with each found to possess a UV-sensitive opsin with a peak absorbance near $360 \mathrm{~nm}$, which is above the $\lambda_{50 \%}$ of all their spectacle scales but is remarkably close to it in the case of the Coachwhip Snake ( $\left.\max \lambda_{50 \%}=355 \mathrm{~nm}\right)$. T. sirtalis and the Coachwhip Snake are also known to possess yellow lenses (Walls, 1931) which likely provide further UV blockage.

The spectacle scale's position as the initial optical filter may be advantageous in that it obviates the need for soft tissues vulnerable to intense radiation to perform this function. However, only in colubrids, elapids, and the odd boid does the spectacle scale attenuate short wavelength UV, indicating that any ocular filtration that might occur in the other boids and in vipers and pythons will nevertheless be accomplished by cellular tissues or the humours. While UV is implicated in cataract development and retinal damage (Sliney, 1986; Taylor, 1989; Gelatt et al., 2013), it has also been implicated in damage of the ocular surface itself, as in certain cases of conjunctival neoplasms and keratitis (Wu et al., 2006; Gelatt et al., 2013). In humans, UV may also influence the development of pterygium which is characterized by anomalous growth of conjunctival tissue from the sclera or limbus over and into the corneal surface (Moran and Hollows, 1984). Mechanisms to minimize radiation-induced damage to the ocular surface should therefore be present in most species exposed to some amount of UV. For the species that bear it, the spectacle may be one such protective structure. One may hypothesize that the coachwhip snake's sharp $\lambda_{50 \%}$ at $\sim 350 \mathrm{~nm}$ may have been an adaptation to its diurnal activities in arid habitats, but the evidence is circumstantial as most colubrids in this study, diurnal or not, and regardless of habitat, have high cut-offs (genus Lampropeltis being the curious exception). Given that several of the vipers in this study (North and Central American rattlesnakes) are deserticolous and active diurnally during some seasons (Landreth, 1973; Golan et $a l ., 1982)$, it would have been compelling were their spectacle scales to exhibit high $\lambda_{50 \%}$ as a protective barrier to UV, but this is clearly not the case. A tangential, but interesting correlation in this regard is the presence of slit or near-slit pupils among the vipers, boas and pythons compared with the rounded pupils of all the sampled colubrids and elapids. Because the crystalline lenses of many colubrids (e.g. genera Masticophis, Coluber, Elaphe) protrude through the pupil, a lower limit 
is set upon the constricted pupil diameter (Lampropeltis can constrict its pupil to rather small dimensions [see photo in Coborn, 1991: 251]). Vipers, boas and pythons are not limited in this regard and can constrict their pupils to smaller areas. While the pupil obviously plays no role in tuning the spectrum, it nevertheless regulates the absolute luminous flux within the eye, which may be protective in itself. An investigation of diurnally-active slit-pupilled colubrids (e.g. some members of subfamily Lycodontinae such as Oligodon ornatus Van Denburgh, 1909) may shed light on whether such a correlation exists between pupil shape and spectacle transmittance.

The conspicuous coloration of the snouted cobra's yellow spectacle stands out in recalling the yellow lenses and corneas of some diurnal terrestrial vertebrates, including the lenses of some snakes and geckos (Walls, 1931; Walls and Judd, 1933; Walls, 1942) and the lenses and corneas of certain fishes (Walls and Judd, 1933; Walls, 1942; Kennedy and Milkman, 1956; Muntz, 1973), which are suggested to function as barriers to UV and/or to increase retinal image contrast. The snouted cobra is not unique among snakes in possessing a yellow spectacle however as the adult Spine-Bellied Sea Snake's spectacle blocks short wavelengths to a similar degree as the snouted cobra and, remarkably, to a much greater degree than the juvenile form of the species as reported by Hart et al. (2012). Because Hart et al. (2012) reported on the whole spectacle, dermis and scale together, it is unknown which layer accounts for the attenuation. The somewhat brown colouration of the hognose snake spectacle scale as observed in this study may also function as a modest filter. The chemical nature of spectacle scale colouration is not known, but may conceivably be related to its specific keratin isoforms or fiber arrangement or it may be contributed by pigments deposited in the scale during keratogenesis or alternatively, it may result from staining by the animals' substrate, such as by tannins or quinone pigments. Spectrophotometric measures and biochemical analyses on shed skins collected in the field or from captive animals kept on specific substrates would be valuable in determining the influence of environmental stains on spectacle scale pigmentation.

\section{Considering the spectacle scale's role as mechanical barrier}

In addition to blocking more deep UV-A, a thicker spectacle scale will offer greater protection against physical injury during locomotion. Walls' (1942) anecdote about observing '.... the sadly scratched and dull appearance of the spectacle of a garter snake inhabiting such an abrasive place as a stone wall' is particularly relevant here; habitat and exposure of the eyes/spectacles due to morphology or method of locomotion may influence evolution of spectacle scale thickness and/or mechanical resistance. Another risk to eyes comes from prey or prey conspecifics disagreeing with the snakes' intentions. This is well illustrated by Bonnet et al.'s (1999) account of a population of Island Tiger Snake (Notechis scutatus (Peters, 1861)) with a disproportionately high incidence of blindness caused by adult gulls protecting their nests. In this light, it is perhaps notable that colubrids generally have thicker spectacle scales than vipers, boas and pythons. The colubrid species investigated in this study lack the vipers' envenomation mechanisms to subdue prey or deter predation, and they similarly lack the boas and pythons overall large size (though there is some overlap in body size, e.g. bull/pine snakes and Puerto Rican Boas).

In regard to the gecko spectacle scale, it is perhaps not surprising that it is so thin since the two species investigated in this study are arboreal insectivores. Unlike snakes who force their heads through abrasive substrate, geckos' eyes rarely encounter anything more harmful than a small shoot or a leaf.

Gecko versus snake spectacle scales and a discussion of keratin composition

Compared with those of snakes, gecko spectacle scales exhibit extraordinarily high transmittance. Though thinner than snakes' at 3-4 $\mu \mathrm{m}$, they are not much thinner than a mojave rattlesnake's $(5 \mu \mathrm{m})$, yet the latter's transmittance profile parallels those of other vipers, including the strong attenuation of UV-B and the much smaller peak at $254 \mathrm{~nm}$. The Marbled Gecko (Gekko grossmanni) is largely nocturnal, requiring little need for protection from $\mathrm{UV}$ radiation. Indeed if $\mathrm{UV}$ is visually relevant to this species, the absence of UV filtration may be advantageous to maximize photon capture. The diurnal Giant Day Gecko (Phelsuma madagascariensis grandis) in contrast will be exposed to as much UV as many diurnal snakes, yet its spectacle scale lets pass a tremendous dose of UV. The gecko spectacle scale appears quite simply to have evolved for maximal transmittance. To reiterate the notion that one must consider the whole eye's spectral transmittance in evaluating an animal's visual capabilities, it should be noted that despite this admission of UV through the gecko spectacle scale, the Giant Day Gecko's retina is nevertheless well shielded (or benefitted by a contrast filter) by virtue of a yellow 
lens (Tansley, 1961). It is not unique in this regard as many diurnal geckos possess yellow lenses (Röll et al., 1996; Röll and Schwemer, 1999; Röll, 2000, 2001).

The spectral properties of a material are related to the chemical composition of that material, and spectacle scales are known to vary in their keratin composition according to family, subfamily, and even between conspecifics and between hatchlings and juveniles (van Doorn et al., 2014). The absence of beta-keratin in gecko spectacle scales (van Doorn et al., 2014) is perhaps most accountable for the observed differences between snake and gecko spectacle transmittance. With their exceptionally high transmittance profiles that parallel published alpha-keratin spectra (horse hair: Bendit and Ross, 1961; human stratum corneum: Bruls et al., 1984), gecko spectacle scales appear to exist at the highest limit of what keratins can transmit. The spectacle scales of snakes, in contrast, attenuate shorter wavelengths in the UV-A and particularly in the UV-B, and will even block or scatter longer wavelengths as evidenced by their gradually tapering transmittance curves. Beta-keratin, for all its beneficial contributions to mechanical protection, does appear to limit spectral transmittance somewhat. It should be borne in mind that the measures reported here were on shed scales which will have been scratched and pitted during the routine activities of the animals (attesting to their protective role!). This may account for some of the spectral attenuation with decreasing wavelength as optical scatter is inversely related to wavelength, but it is unlikely to account for the complete blockage of short wavelength UV-A, UV-B and the reduction or obliteration of the $254 \mathrm{~nm}$ peak in the UV-C (which though not biologically relevant to earthbound animals nevertheless reflects differences in the material).

Another example of keratin's influence on spectral transmittance may be seen in the reticulated python hatchling, whose first shed post-hatch, corresponding with the embryonic integument, exhibits a slightly different transmittance profile, particular around $320 \mathrm{~nm}$ where the trace shows a 'hump' not otherwise seen in the juvenile or adult sheds. Though it wouldn't be visually relevant, it may reflect the different beta-keratin complement of the embryonic integument compared with more mature animals (van Doorn et al., 2014).

\section{Conclusion}

The contribution of the spectacle scale to the spectral properties of the eye varies significantly between taxa, even down to the species-level in some cases. While its effect on the whole eye transmittance of some species may be insignificant (e.g. geckos, vipers, pythons, most boas), in others it may play a substantial role in tuning the visual spectrum (e.g. Snouted Cobra, Hognose Snake) or blocking harmful short wavelengths (e.g. colubrids with sharp cut-offs such as the Coachwhip Snake). Further research is warranted on other families and subfamilies of both snake and gecko of different ecologies. Biochemical analyses may be valuable in determining how keratin isoforms affect transmittance and to determine the nature of the colouration in some spectacle scales.

\section{Acknowledgements}

The authors are indebted to the generous donors of shed snake skins: Rob Caza, Little Ray's Reptile Zoo in Ottawa, Ontario, and the Indian River Reptile Zoo in Indian River, Ontario. Our gratitude extends as well to Prof. Jeff Hovis of the University of Waterloo for his expertise of and assistance with all things spectrophotometric. We also thank two anonymous reviewers for their efforts in reviewing the manuscript and their helpful suggestions on improving it. This work was funded by the Natural Sciences and Engineering Research Council of Canada (NSERC).

\section{References}

Bendit EG, Ross D. 1961. A technique for obtaining the ultraviolet absorption spectrum of solid keratin. Applied Spectroscopy 15: 103-105.

Bonnet X, Bradshaw D, Shine R, Pearson D. 1999. Why do snakes have eyes? The (non-)effect of blindness in island tiger snakes (Notechis scutatus). Behavioral Ecology and Sociobiology 46: 267-272.

Bowmaker JK, Loew ER, Ott M. 2005. The cone photoreceptors and visual pigments of chameleons. Journal of Comparative Physiology A 191: 925-932.

Bruls WAG, Slaper H, van der Leun JC, Berrens L. 1984. Transmittance of human epidermis and stratum corneum as a function of thickness in the ultraviolet and visible wavelengths. Photochemistry and Photobiology 40: 485-494.

Chou BR, Cullen AP. 1984. Spectral transmittance of the ocular media of the thirteen-lined ground squirrel (Spermophilus tridecemlineatus). Canadian Journal of Zoology 62: 825-830.

Coborn J. 1991. The atlas of snakes of the world. TFH Publications.

Da Silva M-AO, Heegaard S, Wang T, Nyengaard JR, Bertelsen MF. 2014. The spectacle of the ball python (Python regius): A morphological description. Journal of Morphology 275: 489-496.

Davies WL, Cowing JA, Bowmaker JK, Carvalho LS, Gower DJ, Hunt DM. 2009. Shedding light on serpent sight: the visual pigments of henophidian snakes. Journal of Neuroscience 29: 7519-7525. 
Doorn KLH van, Sivak JG, Vijayan MM. 2014. Beta-keratin composition of the specialized spectacle scale of snakes and geckos. Canadian Journal of Zoology 92: 299-307.

Douglas RH, Marshall NJ. 1999. A review of vertebrate and invertebrate optical filters. Pp. 95-192 in: Archer SN, Djamgoz MBA, Loew ER, Partridge JC, and Vallerga S, eds, Adaptive Mechanisms in the Ecology of Vision. Dordrecht, Netherlands: Kluwer Academic Publishers.

Duke-Elder S. 1958. The Eye in Evolution. Henry Kimpton Publishing, London, UK.

Ellingson JM, Fleishman LJ, Loew ER. 1995. Visual pigments and spectral sensitivity of the diurnal gecko Gonatodes albogularis. Journal of Comparative Physiology A 177: 559567.

Gelatt KN, Gilger BC, Kern TJ. 2013. Veterinary Ophthalmology 5th Ed. Ames, Iowa: Wiley-Blackwell.

Golan L, Radcliffe CW, Miller T, O’Connel B, Chiszar D. 1982. Prey trailing by the prairie rattlesnake (Crotalus viridis). Journal of Herpetology 16: 287-293.

Hart NS. 2001. The visual ecology of avian photoreceptors. Progress in Retinal and Eye Research 20: 675-703.

Hart NS, Coimbra JP, Collin SP, Westhoff G. 2012. Photoreceptor types, visual pigments, and topographic specializations in the retinas of hydrophiid sea snakes. Journal of Comparative Neurology 520: 1246-1261.

Kennedy D, Milkman RD. 1956. Selective light absorption by the lenses of lower vertebrates, and its influence on spectral sensitivity. Biological Bulletin 111: 375-386.

Landmann L. 1986. The skin of reptiles: epidermis and dermis. Pp. 150-187 in: Bereiter-Hahn J, Matoltsy AG, Sylvia-Richards K, eds, Biology of the Integument, Vertebrates 2. New York: Springer.

Landreth HF. 1973. Orientation and behavior of the rattlesnake, Crotalus atrox. Copeia 1: 26-31.

Loew ER. 1994. A third, ultraviolet-sensitive, visual pigment in the Tokay gecko (Gekko gecko). Vision Research 16: 811-818.

Loew ER, Govardovskiŭ VI, Röhlick P, Szél Á. 1996. Microspectrophotometric and immunocytochemical identification of ultraviolet photoreceptors in geckos. Visual Neuroscience 13: $247-256$.

Lythgoe JN. 1979. The Ecology of Vision. Oxford: Clarendon Press.

Macedonia JM, Lappin AK, Loew ER, Mcguire JA, Hamilton, PS, Plasman M, Brandt Y, Lemos-Espinal JA, Kemp DJ. 2009. Conspicuousness of Dickerson's collared lizard (Crotaphytus dickersonae) through the eyes of conspecifics and predators. Biological Journal of the Linnean Society 97: 749-765.

Maderson PFA. 1985. Some developmental problems of the reptilian integument. Pp. 523-598 in: Gans C, Billett F, Maderson PFA, eds, Biology of the Reptilia, vol. 14 (editors). New York: John Wiley and Sons.

Moran TJ, Hollows FC. 1984. Pterygium and ultraviolet radiation: a positive correlation. British Journal of Ophthalmology 68: 343-346.

Muntz WRA. 1973. Yellow filters and absorption of light by the visual pigments of some Amazonian fishes. Vision Research 13: 2235-2254.

Röll B. 2000. Carotenoid and retinoid - two pigments in a gecko eye lens. Comparative Biochemistry and Physiology A 125: 105-112.
Röll B. 2001. Multiple origin of diurnality in geckos: evidence from eye lens crystallins. Naturwissenschaften 88: 293-296.

Röll B, Schwemer J. 1999. l-crystallin and vitamin A2 isomers in lenses of diurnal geckos. Journal of Comparative Physiology A 185: 51-58.

Röll B, Amons R, de Jong WW. 1996. Vitamin A2 bound to cellular retinol-binding protein as ultraviolet filter in the eye lens of the gecko Lygodactylus picturatus. Journal of Biological Chemistry 271: 10437-10440.

Safer AB, Grace MS, Kemeny GJ. 2007. Mid-infrared transmittance and reflection microscpectroscopy: analysis of a novel biological imaging system: the snake infrared-imaging pit organ. In: Molecular Spectroscopy: The Application Notebook 16-18.

Sillman AJ, Govardovskiŭ WI, Röhlick P, Southard JA, Loew ER. 1997. The photoreceptors and visual pigments of the garter snake (Thamnophis sirtalis): a microspectrophotometric, scanning electron microscopic and immunocytochemical study. Journal of Comparative Physiology A 181: 89-101.

Sillman AJ, Carver JK, Loew ER. 1999. The photoreceptors and visual pigments in the retina of a boid snake, the ball python (Python regius). Journal of Experimental Biology 202: 1931-1938.

Sillman AJ, Johnson JL, Loew ER. 2001. Retinal photoreceptors and visual pigments in Boa constrictor imperator. Journal of Experimental Zoology 290: 359-365.

Sivak JG. 1982. The contribution of the crystalline lens to chromatic and spherical aberration of the eye. Canadian Journal of Ophthalmology 44: 89-91.

Sivak JG, Mandelman T. 1982. Chromatic dispersion of the ocular media. Vision Research 22: 997-1003.

Sliney DH. 1986. Physical factors in cataractogenesis: ambient ultraviolet radiation and temperature. Investigative Ophthalmology and Vision Science 27: 781-790.

Tansley K. 1961. The retina of a diurnal gecko, Phelsuma madagascariensis longinsulae. Pflüger's Archiv für die gesamte Physiologie des Menschen und der Tiere 272: 262-269.

Taylor HR. 1989. The biological effects of UV-B on the eye. Photochemistry and Photobiology 50: 489-492.

Walls GL. 1931. The occurrence of colored lenses in the eyes of snakes and squirrels, and their probable significance. $\mathrm{Co}$ peia 3: 125-127.

Walls GL. 1942. The Vertebrate Eye and its Adaptive Radiation. Hafner Publishing Company, New York, New York.

Walls GL, Judd HD. 1933. The intra-ocular colour-filters of vertebrates. British Journal of Ophthalmology 17: 641-675.

Wu J, Seregard S, Algvere PV. 2006. Photochemical damage of the retina. Survey of Ophthalmology 51: 461-481.

Yang CGY. 2010. Rod-like properties of small single cones: transmutated photoreceptors of garter snakes (Thamnophis proximus). MSc Thesis, University of Toronto, Canada.

Received: 2 June 2014

Revised and accepted: 24 September 2014

Published online: 12 December 2014

Editor: J. van Rooijen 
Table 1. Sampled species from which shed spectacle scales were collected and measured, including their 50\% cut-off wavelengths $\left(\lambda_{50 \%}\right)$ and thicknesses. Thickness measurements are not available for some samples for reasons explained in the text.

\begin{tabular}{|c|c|c|c|c|c|}
\hline Family & Subfamily & Species & Common name & $\begin{array}{l}\lambda 50 \% \quad \mathrm{~T} \\
(\mathrm{~nm})\end{array}$ & $\begin{array}{r}\text { Thickness } \\
(\mu \mathrm{m})\end{array}$ \\
\hline Gekkonidae & Gekkoninae & Gekko grossmanni Günther, 1994 & Marbled gecko & 243 & 4 \\
\hline Gekkonidae & Gekkoninae & Phelsuma madagascariensis (Gray, 1831) & Giant day gecko & $246 / 266$ & 3 \\
\hline Boidae & Boinae & Boa constrictor Linnaeus, 1758 & Boa Constrictor & 317 & 20 \\
\hline Boidae & Boinae & Boa constrictor & Boa Constrictor & 314 & 16 \\
\hline Boidae & Boinae & Boa dumerili (Jan in Jan and Sordelli, 1860) & Dumeril's Boa & 308 & 15 \\
\hline Boidae & Boinae & Boa dumerili & Dumeril's Boa (juvenile) & 308 & 14 \\
\hline Boidae & Boinae & Corallus hortulanus (Linnaeus, 1758) & Garden Tree Boa & 305 & \\
\hline Boidae & Boinae & Epicrates inornatus (Reinhardt, 1843) & Puerto Rican Boa & 318 & 12 \\
\hline Boidae & Boinae & Eunectes murinus (Linnaeus, 1758) & Green Anaconda & 361 & \\
\hline Boidae & Erycinae & Charina bottae (Blainville, 1835) & Rubber Boa & 351 & 18 \\
\hline Colubridae & Colubrinae & Bogertophis subocularis (Brown, 1901) & Transpecos Ratsnake & 336 & 20 \\
\hline Colubridae & Colubrinae & Drymarchon couperi (Holbrook, 1842) & Indigo Snake & 350 & 50 \\
\hline Colubridae & Colubrinae & Elaphe guttata (Linnaeus, 1766) & Corn snake & 339 & 25 \\
\hline Colubridae & Colubrinae & Elaphe guttata & Corn snake (juvenile) & 339 & 18 \\
\hline Colubridae & Colubrinae & Elaphe obsoleta (Say in James, 1823) & Black Ratsnake & 347 & 19 \\
\hline Colubridae & Colubrinae & Elaphe obsoleta & Black Ratsnake & 354 & \\
\hline Colubridae & Colubrinae & Elaphe obsoleta & Black Ratsnake & 334 & \\
\hline Colubridae & Colubrinae & Elaphe obsoleta & Black Ratsnake & 344 & \\
\hline Colubridae & Colubrinae & $\begin{array}{l}\text { Elaphe obsoleta lindheimeri } \\
\text { (Baird and Girard, 1853) }\end{array}$ & Texas rat snake (leucistic) & 355 & 38 \\
\hline Colubridae & Colubrinae & Elaphe obsoleta lindheimeri & Texas Rat snake (leucistic) & 358 & \\
\hline Colubridae & Colubrinae & Elaphe taeniurus Cope, 1861 & Beauty snake & 343 & 33 \\
\hline Colubridae & Colubrinae & Elaphe taeniurus & Beauty snake & 347 & 30 \\
\hline Colubridae & Colubrinae & Elaphe taeniurus & Beauty Snake & 347 & 31 \\
\hline Colubridae & Colubrinae & Lampropeltis alterna (Brown, 1901) & Grey-banded Kingsnake & 313 & 19 \\
\hline Colubridae & Colubrinae & Lampropeltis alterna & Grey-banded Kingsnake & 333 & 20 \\
\hline Colubridae & Colubrinae & Lampropeltis alterna & Grey-banded Kingsnake & 312 & 14 \\
\hline Colubridae & Colubrinae & $\begin{array}{l}\text { Lampropeltis mexicana thayeri } \\
\text { Loveridge, } 1924\end{array}$ & Thayer's Kingsnake & 326 & 20 \\
\hline Colubridae & Colubrinae & $\begin{array}{l}\text { Lampropeltis triangulum hondurensis } \\
\text { K.L. Williams, } 1978\end{array}$ & Honduran MIlksnake & 342 & \\
\hline Colubridae & Colubrinae & Masticophis flagellum flagellum (Shaw, 1802) & Eastern Coachwhip & 355 & 40 \\
\hline Colubridae & Colubrinae & Masticophis flagellum flagellum & Eastern Coachwhip & 340 & \\
\hline Colubridae & Colubrinae & Masticophis flagellum flagellum & Eastern Coachwhip & 350 & 50 \\
\hline Colubridae & Colubrinae & $\begin{array}{l}\text { Masticophis flagellum testaceus } \\
\text { (Say in James, 1823) }\end{array}$ & Western Coachwhip & 354 & \\
\hline Colubridae & Colubrinae & Pituophis catenifer (Blainville, 1835) & Gopher Snake & 348 & 46 \\
\hline Colubridae & Colubrinae & Pituophis catenifer & Gopher Snake & 344 & 30 \\
\hline Colubridae & Colubrinae & Pituophis melanoleucus & Bullsnake & 349 & 38 \\
\hline Colubridae & Colubrinae & Pituophis melanoleucus (Daudin, 1803) & Bullsnake & 344 & 35 \\
\hline Colubridae & Colubrinae & Pituophis melanoleucus & Bullsnake & 350 & 30 \\
\hline Colubridae & Colubrinae & Pituophis melanoleucus & Northern Pine Snake & 350 & \\
\hline Colubridae & Colubrinae & Pituophis melanoleucus & Northern Pine Snake & 351 & 50 \\
\hline Colubridae & Colubrinae & Pituophis melanoleucus & Southern Pine Snake & 349 & 35 \\
\hline Colubridae & Colubrinae & $\begin{array}{l}\text { Pituophis melanoleucus lodingi } \\
\text { Blanchard, } 1924\end{array}$ & Black Pine Snake & 357 & \\
\hline Colubridae & Colubrinae & Pituophis ruthveni Stull, 1929 & Louisiana Pine Snake & 348 & \\
\hline Colubridae & Colubrinae & Spilotes pullatus (Linnaeus, 1758) & Tiger Rat Snake & 356 & \\
\hline Colubridae & Colubrinae & $\begin{array}{l}\text { Thamnophis sirtalis parietalis } \\
\text { (Say in James, 1823) }\end{array}$ & Red-sided garter snake & 338 & 21 \\
\hline Colubridae & Xenodontidae & $\begin{array}{l}\text { Heterodon platirhinos } \\
\text { Latreille in Sonnini and Latreille, } 1801\end{array}$ & Hognose Snake & 381 & \\
\hline Colubridae & Xenodontidae & Heterodon platirhinos & Hognose Snake (juvenile) & 406 & 31 \\
\hline Colubridae & Xenodontidae & Heterodon platirhinos & Hognose Snake (juvenile) & 360 & 25 \\
\hline Elapidae & & Dendroaspis polylepis (Günther, 1864) & Black Mamba & 342 & \\
\hline
\end{tabular}


cont. Table 1.

\begin{tabular}{|c|c|c|c|c|c|}
\hline Family & Subfamily & Species & Common name & $\begin{array}{l}\lambda 50 \% \\
(\mathbf{n m})\end{array}$ & $\begin{array}{r}\text { Thickness } \\
(\mu \mathrm{m})\end{array}$ \\
\hline Elapidae & & Naja annulifera Peters, 1854 & Snouted Cobra & 415 & \\
\hline Elapidae & & Naja pallida Boulenger, 1896 & Red Spitting Cobra & 343 & \\
\hline Pythonidae & & Morelia amethistina (Schneider, 1801) & Amethystine Python & 310 & 16 \\
\hline Pythonidae & & Morelia spilota (Lacépède, 1804) & Carpet Python & 313 & \\
\hline Pythonidae & & Morelia spilota & Carpet Python & 312 & 19 \\
\hline Pythonidae & & Morelia spilota & Carpet Python & 320 & 18 \\
\hline Pythonidae & & Morelia viridis (Schlegel, 1872) & Green Tree Python & 305 & 13 \\
\hline Pythonidae & & Python molurus bivittatus Kuhl, 1820 & Burmese Python & 308 & 20 \\
\hline Pythonidae & & Python molurus bivittatus & Burmese Python & 329 & 10 \\
\hline Pythonidae & & Python molurus bivittatus & Burmese Python (juvenile) & 319 & 15 \\
\hline Pythonidae & & Python regius (Shaw, 1802) & Ball Python & 309 & 15 \\
\hline Pythonidae & & Python reticulatus (Schneider, 1801) & Reticulated Python (first shed) & 312 & 15 \\
\hline Pythonidae & & Python reticulatus & Reticulated Python (juvenile) & 326 & 14 \\
\hline Pythonidae & & Python reticulatus & Reticulated Python (juvenile) & 318 & 13 \\
\hline Pythonidae & & Python reticulatus & Reticulated Python (juvenile) & 334 & \\
\hline Pythonidae & & Python sebae (Gmelin, 1788) & Rock Python & 322 & \\
\hline Pythonidae & & Python sebae & Rock Python & 327 & 21 \\
\hline Viperidae & Crotalinae & Agkistrodon bilineatus Günther, 1863 & Mexican Mocassin & 310 & 15 \\
\hline Viperidae & Crotalinae & Agkistrodon bilineatus & Mexican Mocassin & 325 & 15 \\
\hline Viperidae & Crotalinae & Bothrops neuwiedi Wagler, 1824 & Jararaca Pintada & 324 & 14 \\
\hline Viperidae & Crotalinae & Crotalus basiliscus (Cope, 1864) & Mexican West Coast Rattlesnake & 317 & \\
\hline Viperidae & Crotalinae & Crotalus durissus vegrandis Klauber, 1941 & Uracoan Rattlesnake & 310 & 15 \\
\hline Viperidae & Crotalinae & Crotalus mitchellii pyrrhus (Cope, 1867) & $\begin{array}{l}\text { Southwestern Speckled } \\
\text { Rattlesnake }\end{array}$ & 320 & \\
\hline Viperidae & Crotalinae & Crotalus oreganus helleri Meek, 1905 & Southern Pacific Rattlesnake & 319 & \\
\hline Viperidae & Crotalinae & Crotalus scutulatus (Kennicott, 1861) & Mojave Rattlesnake & 307 & 5 \\
\hline Viperidae & Crotalinae & Crotalus atrox Baird and Girard, 1853 & Western Diamondback & 320 & \\
\hline Viperidae & Crotalinae & Trimeresurus erythrurus (Cantor, 1839) & Redtail Viper & 303 & \\
\hline Viperidae & Viperinae & $\begin{array}{l}\text { Bitis gabonica } \\
\text { (Duméril, Bibron and Duméril, 1854) }\end{array}$ & Gaboon Viper & 331 & 22 \\
\hline
\end{tabular}

